University of Nebraska - Lincoln

DigitalCommons@University of Nebraska - Lincoln

Faculty Publications from Nebraska Center for Research on Children, Youth, Families, and Schools
Children, Youth, Families \& Schools, Nebraska Center for Research on

2008

\title{
Context Influences Preschool Children's Decisions to Include a Peer with a Physical Disability in Play
}

\author{
Karen E. Diamond \\ Purdue University, kdiamond@purdue.edu \\ Soo-Young Hong \\ University of Nebraska - Lincoln, shong5@unl.edu \\ Huifang Tu \\ University of Tennessee
}

Follow this and additional works at: https://digitalcommons.unl.edu/cyfsfacpub

Part of the Pre-Elementary, Early Childhood, Kindergarten Teacher Education Commons

Diamond, Karen E.; Hong, Soo-Young; and Tu, Huifang, "Context Influences Preschool Children's Decisions to Include a Peer with a Physical Disability in Play" (2008). Faculty Publications from Nebraska Center for Research on Children, Youth, Families, and Schools. 24.

https://digitalcommons.unl.edu/cyfsfacpub/24

This Article is brought to you for free and open access by the Children, Youth, Families \& Schools, Nebraska Center for Research on at DigitalCommons@University of Nebraska - Lincoln. It has been accepted for inclusion in Faculty Publications from Nebraska Center for Research on Children, Youth, Families, and Schools by an authorized administrator of DigitalCommons@University of Nebraska - Lincoln. 


\title{
Context Influences Preschool Children's Decisions to Include a Peer with a Physical Disability in Play
}

\section{Karen E. Diamond* and Soo-Young Hong}

Purdue University

\section{Huifang Tu}

University of Tennessee

\begin{abstract}
Understanding children's decisions to include a child with a disability in activities is an important component of the social environment of children with disabilities. We examined preschool children's understanding of the motor and social competence of hypothetical children with a physical disability, children's decisions to include or exclude a peer with a physical disability in play activities, and children's justifications of their inclusion/exclusion decisions. Children understood that a peer with a physical disability would have more difficulty with activities requiring motor skills than social skills and were more likely to include a peer with a physical disability when the activities required minimal motor skills. The role of typically developing children's understanding of social contexts in peer relationships is discussed.
\end{abstract}

There has been substantial attention to the role of inclusive educational settings in supporting the development of young children with disabilities. Scholars (Guralnick, 2001; Odom et al., 2006) have suggested that the peer group in inclusive settings may provide "more age-appropriate, competent and positive models" (Odom et al., 2006, p. 807) of development than in special education classrooms. Approximately half of preschool children with disabilities receive special education in programs that include typically developing peers (U.S. Department of Education, 2004), and one-third to two-thirds of preschool programs designed for typically developing children include at least one child with a disability (Buysse, Wesley, Bryant, \& Gardner, 1999; McDonnell, Brownell, \& Wolery, 1997). In addition, young children with disabilities participate in community activities, including recreation and religious programs, with peers who are typically developing (Beckman \& Hanson, 2002). This suggests that there are multiple opportunities for children with disabilities to participate in school and community programs that include peers without disabilities. It is reasonable to expect that the potential of inclusive settings to support children's development is enhanced when children with disabilities are accepted by and have multiple opportunities for social interaction with their peers.

*Corresponding author: Department of Child Development and Family Studies, Purdue University, West Lafayette, Indiana; kdiamond@purdue.edu 
Teachers in inclusive programs report that many young children with disabilities have friends who are typically developing and that the number of friends does not differ significantly between children with disabilities and their peers (Buysse, Goldman, \& Skinner, 2002). Substantial numbers of preschool children with disabilities are wellaccepted by classmates, with acceptance reflected in positive peer ratings and social interactions (Odom et al., 2006). These children are likely to reap many developmental benefits of inclusive settings, including benefits related to social and communicative competence (Odom \& Diamond, 1998).

Despite the evidence that many young children with disabilities have at least one friend, observations in inclusive preschool classrooms provide consistent evidence that children with disabilities are included in social interactions with their peers less frequently than are children without disabilities (cf. Brown, Odom, Li, \& Zercher, 1999; Guralnick et al., 1996). Odom and colleagues found that a substantial proportion of young children with disabilities were at risk for explicit rejection by the peer group. Noteworthy is the additional finding that almost half the children with disabilities in the classrooms that Odom and colleagues observed were "average" and were neither actively accepted nor rejected by their peers (Odom et al., 2006). Taken together, these studies suggest that while peer-related social interactions tend to occur less frequently for many young children with disabilities than for their peers, there is substantial variability in social acceptance and friendships across the group of young children with disabilities.

Differences in children's social interactions with and acceptance by peers may reflect cognitive, social problem solving and emotion regulation limitations associated with a child's disability and with lower levels of peer-related social competence (Diamond, 2002; Harper \& McCluskey, 2002; Odom et al., 2006). Yet, children with physical and sensory disabilities and health problems requiring frequent hospitalization, such as asthma, who do not have cognitive limitations, may be at greater risk for social isolation than are typically developing children (Diamond, 2002). Results such as these provide a reminder that social relationships are multifaceted and that it may be productive to explore the perspectives of both partners in the interaction. In inclusive settings, social interactions for young children with disabilities often include a typically developing peer (Guralnick, 1999). Understanding typically developing children's ideas about what it means to have a disability and children's decisions to include a child with a disability in activities with peers, along with individual children's peer-related social competence, can be critical for understanding the social environment of children with disabilities.

Young children's understanding of disabilities appears to follow a predictable developmental progression, Conant and Budoff (1983) found that preschool children expressed awareness (i.e. agreed that it might be possible for someone to have difficulty with a specific skill) of sensory and physical disabilities but not of mental retardation or emotional disturbance. Preschool children were aware that it would be possible for someone to be unable to see or hear or to have difficulty walking, even when they had had no direct experience with individuals with these disabilities. Awareness that someone might have difficulty thinking or managing emotional responses did not appear until later in childhood and early adolescence. They suggested that because sensory and orthopedic disabilities were highly noticeable and perceptually salient, it increased the likelihood that young children would have a basic understanding of these disabilities. 
Diamond and Hestenes (1996) found that a majority of preschool children recognized photographed children with disability-related equipment (e.g. a child with a hearing aid, a child using a wheelchair) as different from themselves. None of the 46 children in their study recognized a photograph of a child with Down syndrome to be a child with a disability, providing additional evidence that preschool children may not be sensitive to distinctive features associated with a disability such as Down syndrome. In separate studies with preschool and kindergarten children, Diamond (1993) and Favazza and Odom (1997) found that children focused on concrete features (e.g. equipment: "He can't hear because he has that thing [hearing aid] in his ear") or on things that they already knew about (e.g. accidents: "He can't walk because he broke his leg") to explain a child's disability. Preschool children frequently used age or ability to explain a child's disability-related difficulties in some activities. Diamond (1993) found that children appeared to use age as a proxy for ability in their explanations for a child's difficulty in talking or walking (e.g. "When he gets bigger he can walk like everybody else"). These explanations were used even when the child with a disability was bigger than the child providing the explanation, Results such as these are important because they suggest that while preschool children may not be sensitive to features that identify some children as having a disability (e.g. children with Down syndrome), young children are aware of and try to understand noticeable features, such as equipment, that characterize some children and adults with disabilities.

In addition to evidence that young children have a basic understanding of physical and sensory disability, preschool children appear to be able to distinguish among developmental skills of individuals with different disabilities. Diamond (1994) used photographs of children with sensory and orthopedic impairments to understand preschool children's ideas about the consequences of a disability for participation in different age-appropriate activities. She found that preschool children said that someone in a wheelchair would be significantly less competent than a typically developing peer at tasks requiring motor skills (e.g. throwing a ball, climbing a ladder) but not at tasks with few physical demands (e.g. reading a book, listening to music), Nabors and Keyes (1997) found similar results in a study of preschool children's reactions to hypothetical children who had an orthopedic impairment (in a wheelchair or with a leg brace) or a facial scar, or who were physically able, In this study, children expressed much stronger preferences for interacting with the physically able child or with the child with a facial scar than with a child with an orthopedic impairment on the playground. However, such preferences were not apparent when children were asked about contexts requiring lower levels of motor activity, such as eating. These results suggest that children's playmate preferences may be influenced, in some cases, by relationships between a child disability and the functional demands of the situation.

The studies just described focus on children's ideas about disability. They provide evidence that many preschool children express awareness of orthopedic and sensory disabilities, use their experiences to understand the disability, and are sensitive to the ways in which a physical disability affects some, but not other, skills. In the present study, we examine the ways in which the demands of an activity (i.e. the extent to which the activity requires physical motor skills) are related to preschool children's decisions to include an unfamiliar child with a physical disability in play activities. Based on previous research evidence, we hypothesize the 
preschool children will give lower ratings of motor than of social competence to a hypothetical child with an orthopedic impairment who uses a wheelchair. In addition, we hypothesize that preschool children will be more likely to say that they would include a child with a physical disability in an activity that requires fewer motor skills than in an activity with substantial motor demands.

In addition to examining the importance of functional context in children's inclusion decisions, we also examine children's explanations of their decisions. Understanding children's reasoning about decisions related to inclusion or exclusion of age mates from specific play activities is important, particularly since children's explanations of their decisions are likely to reflect both their own experiences and their understanding of social norms (Killen \& Stangor, 2001), Unfortunately, little research has focused on the role of disability in children's social decisions, but studies of young children's use of gender and gender stereotypes in decision making are informative. There is substantial research evidence that gender is a salient characteristic for preschool children, with gender stereotypes related to a variety of judgments about others (Fabes, Martin, \& Hanish, 2004; Martin, Ruble, \& Szkrybalo, 2002).

In a series of studies, Killen and colleagues examined children's ideas about the morality of excluding peers from play groups on the basis of gender stereotypes (Killen \& Stangor, 2001; Theimer, Killen, \& Stangor, 2001), When faced with a situation in which they had to choose between two children who were equally qualified, most preschool children excluded the non-stereotypic child from the activity (e.g. excluded a girl from playing with trucks or a boy from playing with Barbie dolls). Although young children appeared to use gender-role stereotypes in their initial decisions, most preschool children judged straightforward exclusion (e.g. He can't play with dolls because dolls are for girls) as wrong. Findings such as these suggest that even young children use a variety of different, sometimes conflicting, information in making decisions about hypothetical playmates.

In this study, we focus on children's ideas about and justifications for including or excluding a child with a physical disability in different play contexts. We chose to focus specifically on physical disability because there is substantial evidence that preschool children have a basic understanding of this disability (cf, Conant \& Budoff, 1983; Diamond, 1994; Nabors \& Keyes, 1997). We were interested in children's ideas about someone with a disability rather than in the ways in which children understand different disabilities. Others have found no significant differences in young children's ideas about acceptance as a function of type of disability (Diamond \& Hestenes, 1996), and the generic term "handicapped" has often been used to elicit young children's attitudes toward individuals with disabilities (Favazza \& Odom, 1997). We use hypothetical scenarios rather than asking children about specific friends because of our interest in understanding the ways in which children coordinate ideas about disability with their understandings of the functional demands of specific activity contexts.

\section{Method}

Participants were recruited from preschool and child-care programs in a midsize, Midwestern city. All the programs included children with identified disabilities, although no children with orthopedic impairments who required the use of a wheelchair were enrolled at the time of this study. Letters of invitation describing 
the research, along with consent forms, were sent to parents of all English-speaking three- to six-year-old children $(N=61)$; 46 children (20 boys; mean age of participants $=52.9$ months, $\mathrm{SD}=7.1)$ had permission to participate. Most children were European-American $(n=37) ; 1$ child was of Hispanic and 8 children were of Asian backgrounds.

\section{Procedure}

Each child participated in an individual interview that lasted approximately 20 minutes. Interviews were completed in a small room that was away from the child's classroom. Dolls and drawings were used to illustrate the interview questions, as others have found that dolls, puppets, and drawings are familiar materials that attract children's interest and lessen-processing demands (Ramsey, 1988; Theimer et al., 2001).

Interview questions focused on physical disability. Two dolls, one in a wheelchair and one standing, that were both the same gender as the participating child, were used to illustrate these questions. The disability of the doll in the wheelchair was described to the child at the time the doll was introduced (e.g. "This doll's sitting in a wheelchair because s/he can't walk. His/her legs don't work. I want you to pretend that this doll is a real girl/boy who can't walk"). Interviews included two parts: children's evaluations of social and motor competence for this hypothetical child (doll) with a physical disability and vignettes that focused on decisions about whether to include a hypothetical child in a wheelchair or a typically developing child in different activities. Vignettes have been used in studies of the role of gender in young children's decisions (e.g. Theimer et al., 2001) and in studies of older children's acceptance of hypothetical children with mental retardation (Manetti, Schneider, \& Siperstein, 2001).

\section{Measures}

We began with warm-up questions to ensure that children understood that one doll could walk while the other doll could not walk but used a wheelchair to move around. The interviewer introduced the two dolls to the child and said, "Look at these dolls. Let's pretend they are real children. I am going to tell you some stories about them and ask you some questions." Then the interviewer asked the child to "show me the one that cannot walk." If the child answered correctly, the interviewer said, "That's right. This doll cannot walk. She uses her wheelchair to move around," If the child answered incorrectly, the interviewer would say, "No, this doll (point to the doll in the wheelchair) cannot walk. He uses the wheelchair to move around." (No child answered this question incorrectly.)

Evaluation of social and motor competence. We asked children to rate the participation of a child with a physical disability (represented by the doll in the wheelchair described above) in activities that required motor skills and in social relationships with peers. The format of this rating scale and the wording of individual items are identical to those first described by Harter and Pike (1984), Similar versions of this measure have been used in previous research on young children's ideas about disabilities (Diamond, Hestenes, Carpenter, \& Innes, 1997), This scale has been shown to be reliable, with test-retest correlations for ratings of typically developing children ranging from 0.87 (peer acceptance) to 0.94 (language skills; Diamond, 1993). 
For each item there was a drawing on one side of a page of a child who performed the task well (e.g. was very good at running or had lots of friends) and a second drawing on the other side of the page of a child who was less competent at the task (e.g. was not very good at running or did not have many friends), The placement of the drawings on the right or left side of the page was counterbalanced across the eight items so as to control for position preferences in children's selections.

For each item, one picture was pointed to and described (e.g. "This girl is pretty good at running" or "has lots of friends to play with,"), and then the second drawing was pointed to and described (e.g. "This girl isn't very good at running" or "doesn't have many friends to play with,"). The child was then shown the doll in the wheelchair and was asked to point to the drawing that best described that doll (e.g. "If this were a real girl, do you think she would be pretty good at running or not very good at running" or, "have a lot of friends to play with or not very many friends?"). After the child chose a drawing, she was asked if the doll was "a lot like" or "a little bit like" the child in the drawing. The child's selection provided a score from I (the child thinks the doll would be like the girl who is not very good at the task) to 4 (the child thinks the doll would be like the girl who is pretty good at the task). Mean competency ratings were calculated for four social items and, separately, for four motor tasks. Higher scores represent greater competence at the task. There are separate versions of the scale for boys and girls that use the same items but use gender-appropriate wording and line drawings. Internal consistency reliabilities in this sample were good (social: $\alpha=0.78$; motor: $a=0.71)$.

Inclusion vignettes. We used six vignettes to talk with children about whether they would choose to include a child with a physical disability or a typically developing child in an activity. Activities varied systematically in terms of functional motor demands: two of the vignettes focused on activities that required substantial motor skills and would need to be adapted for a child in a wheelchair (kicking a ball, dancing) and two had more modest motor skills requirements; these activities would have been somewhat difficult because the child in the wheelchair needed help gaining access to the activity (e.g. completing a puzzle on the floor required a teacher's help to move from the wheelchair). An additional two activities had minimal motor skills requirements and the child's physical disability was described as not interfering with participation. (A copy of the vignettes is included in the Appendix.) Children's responses were audio taped and transcribed for later coding.

We began by describing a situation in which two children (represented by the dolls) wanted to participate in an activity but there was room for only one more child. (This is a common occurrence in preschool classrooms where teachers often limit the number of children who can play at an activity.) The vignettes varied in required functional motor skills, but we did not emphasize this difference. Instead, we offered a suggestion about how each child might participate and then asked the child to choose one doll. For example, in the dancing vignette, the child was told that the doll in the wheelchair could "dance by moving his arms" and that the child who was standing could "dance with his arms and his legs." After making a decision, we asked children to explain their reasoning ("Why did you choose this girl/boy?"). 
The first and third author read 25\% of children's explanations independently and each developed categories, inductively, that best reflected children's responses. Final agreement on coding categories was reached after discussion. The most common categories included those in which children referred to equipment ("She should get to dance because she does not have a wheelchair") or a child's ability ("He can't dance because he can't stand up"). Some children explained their decisions by referring to sharing, fairness, and taking turns ("He can do it first but then the other boy gets a turn,") or to enjoyment ("She should get to do it because she likes to"). A few children provided explanations that referred to a child's experience ("She should make pictures because she's never done it before"), although experience was not included in the vignette.

Children's decisions about which child should play were coded dichotomously: " $I$ " if the child chose the doll in the wheelchair or " 0 " if the child chose the typically developing doll. The number of times the child selected the doll in the wheelchair was used in analyses. Total scores could range from 0 (the child never chose the doll in the wheelchair) to 6 (the child chose the doll in the wheelchair for each vignette) and from 0 to 2 for each of the three types of vignettes, Inter-rater reliability was $100 \%$ agreement for choice of doll.

The third author and a graduate assistant independently coded all children's explanations with the coding scheme described above. Inter-rater reliability was $85 \%$ exact agreement for explanations. Both coders reviewed and coded all transcripts, and disagreements in codes were resolved through discussion.

\section{Results}

We examined relations between age, gender, and children's decisions in preliminary analyses, There were significant gender differences: girls $(\mathrm{M}=2.11, \mathrm{SD}=$ $1.5)$ were significantly more likely than boys $(M=1.14, S D=1.28)$ to choose a child with a disability $(F(1,45)=5.42, p=0.02$, partial eta squared $=0.11)$, Age was not significantly related to the frequency of children's choice of a child with a disability $(r(46)=0.04)$.

We examined the proportion of vignettes in which children selected the doll in the wheelchair to play, Children were significantly more likely to choose a typically developing child $(\mathrm{M}=4.2)$ than a child with a disability $(\mathrm{M}=1.8 ; t[46]=-7.41$, $p<0.001, d=1.07)$.

We hypothesized that children would give significantly different and higher social competence than motor skills ratings to the hypothetical child in the wheelchair, reflecting an understanding that it would be more difficult for a child with a physical disability to participate in motor than in social activities. A repeated measures analysis of variance (ANOVA) with motor and social competence ratings as the repeated, withinsubjects measure, and gender as the between-subjects variable, revealed a significant, moderate within-subjects main effect for competence $(F(1,45)=7.14, p=0.01$, partial eta squared $=0.14)$, Children gave significantly higher mean ratings to items assessing social $(\mathrm{M}=2,88, \mathrm{SD}=0.97)$ compared with motor $(\mathrm{M}=2.41, \mathrm{SD}=0.85)$ competence, There was no significant effect of gender $(F(1,45)=0.007)$ and no significant gender $X$ competence interaction $(F(1$, $45)=0.89$ ).

We hypothesized that children's inclusion decisions would be related to the functional motor demands of the activity, with children less likely to choose 
the doll in the wheelchair for activities requiring substantial (e.g. kicking) compared with minimal motor skills (e.g. a table-top art activity), A repeated measures ANOVA was used to evaluate this hypothesis, Motor demands of the activity (substantial, moderate, minimal) was the within-subjects repeated measure, and gender was the betweensubjects variable, The number of times that a child selected the doll in the wheelchair was the dependent variable. Results of this analysis revealed a significant and moderate multivariate effect for functional motor skills $(F[2,90]=6.53$, Wilk's Lambda $=0.771, p<0.001$, partial eta squared $=0.23)$ and a significant but modest between-subjects effect for gender $(F[1,45]=6.02, p<$ .005 , partial eta squared $=0.12)$, There was no activity $X$ gender interaction $(F[2,90]$ $=1.52$, Wilk's Lambda $=0.993)$, Withinsubjects contrasts revealed that children were significantly more likely to say they would include a child with a disability in activities that required minimal functional motor skills than those that required moderate $(F[1,45]=10.17, p=.003$, partial eta squared $=0.18)$ or substantial motor skills $(F[1,45]=13.98, p=0.001$, partial eta squared $=0.24)$. We found no significant difference in inclusion for activities requiring moderate or significant motor skills. Girls $(M=0.71)$ were significantly more likely than boys $(M=0.38)$ to choose the child in the wheelchair, regardless of activity (see Table 1).

Next, we examined the reasons that children offered for their decisions. Most children referred to the wheelchair or made comments about a child's ability. Fortyone of forty-six children referred to the doll's wheelchair to explain at least one decision. Some children referred to the absence of equipment (e.g. "He doesn't need a wheelchair"), while other children referred specifically to the wheelchair (e.g. "She's in a wheelchair so she couldn't do it") to explain their choice of the typically developing child. In addition, some children described the child they had chosen by referring to the wheelchair (e.g. "He gots a wheelchair"), but it was not possible to determine how this explained their decision, and follow-up questions yielded no further information. Given these varied uses of equipment in explanations, it is perhaps not surprising that there was not a significant relation between the number of times children referred to equipment and the frequency of choosing a child with a disability to participate in an activity $(r(39)=-0.19, p=0.21)$.

Thirty-nine children referred to ability in at least one of their explanations. Children referred to a child's ability in two different ways to explain their decisions: some children referred to the typically developing child's ability to participate in an activity to justify why they chose that child (e.g. "She's good at kicking"). Children also referred to the disability of the hypothetical child in a wheelchair to explain their choice of the typically developing doll (e.g. "I chose this one [typically developing] because he [child in a wheelchair] can't dance"). Occasionally, children referred to both equipment and ability to explain their choice of the doll in the wheelchair (e.g. "She's in a wheelchair, but she can just move it up to the table and then she can make a picture"). These responses were coded as referring to equipment. Among the 39 children who used ability to explain at least one decision, there was a significant negative correlation between children's choice of a child with a disability and the number of times the child relied on ability to justify a decision $(r(39)=-0.41, p=0.009)$.

Occasionally, children's justifications reflected issues of justice and equity, explanations that Killen and colleagues refer to as moral (Killen, Pisacane, Lee-Kim, \& Ardila-Rey, 2001). These types of explanations were offered at least once by 18 
Table 1

Descriptive Statistics of the Frequency of Choosing a Child with a Disability in Activities with Different Motor Demands

\begin{tabular}{lllcc} 
& & \multicolumn{2}{c}{$95 \%$ Confidence Interval } \\
Gender & Motor Demands & Mean (SD) & Lower Bound & Upper Bound \\
Boy $(n=20)$ & Substantial & $0.20(0.16)$ & -0.11 & 0.51 \\
& Moderate & $0.40(0.16)$ & 0.08 & 0.73 \\
& Minimal & $0.55(0.16)$ & 0.23 & 0.87 \\
Girl $(n=26)$ & Substantial & $0.56(0.13)$ & 0.29 & 0.83 \\
& Moderate & $0.56(0.14)$ & 0.28 & 0.84 \\
& Minimal & $1.15(0.14)$ & 0.88 & 1.42
\end{tabular}

Note: Scores can range from $0-2$.

children. Explanations in this category included references to sharing and inclusion ("There's enough room for both of them-everybody can share"). Because it was highly skewed, we recoded moral explanations into a dichotomous variable on the basis of whether children ever referred to sharing and inclusion as an explanation for their choice. We then examined relationships between the use of this explanation and the number of times children chose a child with a disability in a 2 (moral explanation: ever, never) X 2 (gender) ANOVA, There was a significant main effect for gender $(F[1,45]=6.88, p=0.01$, partial eta squared $=0.14)$ but not for explanation $(F[1,45]=0.012)$, and there was not a significant interaction, A subsequent $X^{2}$ analysis revealed that girls (15 of 26) were more likely than boys ( 3 of 20$)$ to justify a response by referring to sharing or enjoyment $\left(X^{2}(1)=\right.$ $11.12, p=0.001)$.

Finally, we found no significant relationships between the number of times children chose a child with a disability and their ratings of motor $(r[46]=0.21, \mathrm{p}=0.15)$ or social $(r[46]=0.09, p=0.55)$ competence for a child in a wheelchair, Ratings of motor competence were significantly and negatively associated with the number of times a child used ability to explain his or her choice $(r[46]=-0.38, p=0.01)$.

\section{Discussion}

As have others (Guralnick et al., 1996), we found that preschool children were, overall, more likely to choose a child who was typically developing, rather than a child with a physical disability, to participate in a variety of activities. Girls were more likely than boys to choose a child with a disability across all activity settings.

We found that children had somewhat different views when asked about motor and social competence of a hypothetical child who used a wheelchair. Children gave significantly lower ratings for motor than for social competence, suggesting that preschool children understood that a child with a physical disability (in this case, a child in a wheelchair) would find tasks requiring difficult motor skills (cf. Conant \& Budoff, 1983; Diamond 1994), We note, however, that even though ratings were significantly different, mean social competence ratings reflected an assessment that the child would be, at most, "sort of good" at social interactions. Given this, it is perhaps not surprising that children's social competence ratings were not significantly associated with their choice of a child in a wheelchair to play at different activities. Because we did not ask children to provide competence rat- 
ings for the typically developing doll, we do not know whether there would be similar differences in social competence ratings and choice of the typically developing doll. These results suggest, at least, that children may think about the social context in different ways, depending on the question that is asked.

Children's decisions to include a child with a physical disability were related to the motor skills that were required for the activity. Children were significantly more likely to choose a child in a wheelchair to participate in play when the activity required minimal motor skills. These results are consistent with those of Nabors and Keyes (1997) who found that preschool children were more likely to prefer to play with a hypothetical child in a wheelchair when the activity required modest motor skills, such as eating lunch, than on the playground, Although we attempted to create vignettes that represented activities requiring a range of motor skills, these preschool children seemed to find little difference between activities requiring moderate and those requiring substantial motor skills. We do not know whether this is a function of the measurement approach or reflects children's ways of thinking about participation of a child with a physical disability in different activities.

The results of this study provide additional evidence that at least in some circumstances, preschool children use both situational demands and individual characteristics in making decisions about who should play, Many of the preschool children in this study understood that someone in a wheelchair is likely to have difficulty with tasks requiring moderate or substantial motor skills and that some activities require more motor skills than do others. Children coordinated their understanding of physical disability and of different activities when making a decision about which of two hypothetical children should be chosen to participate in a specific activity. Of note is that the relationships that we found between activity context and the frequency with which children selected a child in a wheelchair were moderately strong.

In earlier studies, Diamond and colleagues (Diamond, 1993; Diamond \& Kensinger, 2002) found that preschool children were aware of some behaviors, such as speech and language delays, that may be another aspect of a child's disability. Others have found that young children may use overt physical characteristics, such as race and gender, as a basis for discriminations among potential playmates (Ramsey \& Myers, 1990). Even though preschool children do not have a complete understanding of what it might mean to have a disability, our findings suggest that disability, particularly one associated with easily recognized equipment such as a wheelchair, may serve as a basis for discriminating among potential playmates for some types of activities. It is important to note that although children were more likely to exclude a child in a wheelchair from activities requiring moderate or substantial motor skills this was not the case for activities requiring minimal motor skills. Children were significantly more likely to say they would include the child in a wheelchair when the activity required minimal motor skills, and girls were at least as likely to choose the child in the wheelchair as the typically developing child for these activities.

In addition to asking children to choose a doll to play in the activity, we also asked children to provide an explanation for their choice. This is a task that requires substantial cognitive and language abilities, and it is hardly surprising that children occasionally offered responses that were not easily interpreted. This was 
particularly the case when children referred to a child's wheelchair: in some situations, the wheelchair was clearly an indication that one child (with a wheelchair) would have more difficulty with a task than would another (the typically developing child), while in other situations it appears as though children used the wheelchair as a descriptor, much as they might have referred to a child's hair color or other salient physical features. To the extent that children referred to the wheelchair in their explanations, it suggests that wheelchairs are a particularly noteworthy feature. This is not surprising, as children are likely to have seen children or adults in wheelchairs while shopping with parents or at community events. In fact, advice columns for parents often include suggestions about how to respond to children's public questions about others, including people with physical disabilities (van der Meer, 2007).

Unlike their use of equipment to describe the child as well as to explain their choice, children's uses of ability explanations were more closely tied to their selection of the typically developing doll. As we noted earlier, children used ability in two different ways, In some instances, children referred to the ability of the typically developing child, and in others they referred to the difficulty that the child in the wheelchair would have participating in an activity. The relationships between children's references to ability in their explanations and their choice of the typically developing doll occurred despite our efforts to identify a way in which the child in the wheelchair might participate in each activity. For example, when the activity involved dancing to ABC Rock, we told children that while the child in the wheelchair could not move her legs, she could dance by moving her arms, We do not know what children thought of this suggestion, although it is likely to be similar to suggestions that teachers might offer (Kemple \& Jalongo, 2003), Clearly, it was not very convincing, because most children selected the typically developing child when the activity required motor skills, and frequently justified their choices by referring to one child's ability or the other child's disability.

It is important to note that we did not observe children's interactions with peers. The relationships between children's ideas and their interactions are complex (Manetti et al., 2001; Okagaki, Diamond, Kontos, \& Hestenes, 1998), One advantage of using hypothetical vignettes to explore children's ideas, as we did, is that the vignettes serve to elicit children's ideas independently of their friendships (or lack of friendship) with specific individual children with disabilities. Interactions between young children reflect more than the demands of the activity; they also reflect the individual characteristics of each child, including shared interests in play activities and social interactions. In a study of children's social interactions in preschool, Ramsey (1995) found that children developed more selective peer preferences and interaction patterns over the course of the school year and that fourand five-year-old preschool children were significantly less likely to participate in mixed-gender play groups in the spring than in the fall Results such as these highlight the importance of understanding the social contexts of inclusive classrooms along with the functional demands of classroom activities in understanding opportunities for interaction among children with disabilities and their typically developing peers. These findings also raise concerns about potential social experiences of young boys with disabilities. We found that girls were significantly more likely than boys to select a doll in a wheelchair. To the extent that young children become increasingly likely to participate in same-sex playgroups during 
preschool, it suggests that social interaction opportunities for boys with disabilities may be limited.

There is substantial evidence that skills, including emotion regulation and social problem solving, are important in the development of social competence for young children with disabilities (Diamond, 2002). Having these social skills does not automatically mean, however, that a child experiences high levels of social acceptance. As we noted earlier, Odom and colleagues (2006) found that approximately half of the children with disabilities whom they observed in inclusive preschool classrooms were neither socially accepted (with peer ratings above the median for the class) nor rejected. While they identified some behavioral characteristics that distinguished children in the socially accepted group, we wonder if the "average" children might have been rated more highly by a different peer group, It is important that we understand the individual characteristics that support children's interactions with peers. It is also important that we have a better understanding of the role of the peers in supporting children's social competence.

Although they do not necessarily represent specific interactions with peers, the ideas that are reflected in these children's responses reflect their understandings of a variety of different social demands, including an understanding of physical disability and the functional demands of different activity contexts. Children's responses also reflect their understanding of the extent to which it is acceptable to exclude a child from play. Understanding the ways in which a child's interactions with his or her classmates contribute to children's ideas about people with disabilities and to the later development of children's ideas about others remains an important research goal.

Acknowlegments

The authors would like to thank Jodi Putnam for her assistance with data collection. This research was supported in part by funds from the Kinley Trust and the Agricultural Research Programs at Purdue University.

\section{References}

Beckman, P.J., and M.J. Hanson (2002). Community participation of children with disabilities. In: S.L. Odom (Ed.), Widening the Circle: Including Children with Disabilities in Preschool Programs (pp. 120136). New York: Teachers College Press.

Brown, W.H., S.L. Odom, S. Li and C. Zercher (1999). Ecobehavioral assessment in early childhood programs: a portrait of preschool inclusion. Journal of Special Education 33: 138153.

Buysse, V., B.D. Goldman and M.L. Skinner (2002). Setting effects on friendship formation among young children with and without disabilities. Exceptional Children 68: 503-517.

Buysse, V., P.W. Wesley, D. Bryant and D. Gardner (1999). Quality of early childhood programs in inclusive and noninclusive settings. Exceptional Children 65: 301-314.

Conant, S., and M. Budoff (1983). Patterns of awareness in children's understanding of disability. Mental Retardation 21: 119-125.

Diamond, K.E. (1993). Preschool children's concepts of disability in their peers. Early Education and Development 4: 123-129.

Diamond, K.E. (1994). Evaluating preschool children's sensitivity to developmental difference in their peers. Topics in Early Childhood Special Education 14: 49-63.

Diamond, K.E. (2002). Social development of children with special needs. In: C. Hart and P. Smith (Eds.), Handbook of Social Development (pp. 571-587). London: Blackwell.

Diamond, K.E., and L. Hestenes (1996). Preschool children's conceptions of disabilities: the salience of disability in children's ideas about others. Topics in Early Childhood Special Ed- 
ucation 16: 458-475.

Diamond, K.E., L. Hestenes, E. Carpenter, and F. Innes (1997). Relationships between enrollment in an inclusive class and preschool children's ideas about people with disabilities. Topics in Early Childhood Special Education 17: 520-536.

Diamond, K.E., and K. Kensinger (2002). Vignettes from Sesame Street: preschooler's ideas about children with Down syndrome and physical disability. Early Education and Development 13: 409-421.

Fabes, R.A., C.L. Martin and L.D. Hanish (2004). The next 50 years: considering gender as a context for understanding young children's peer relationships. Merrill-Palmer Quarterly 50: 260-273.

Favazza, P., and S.L. Odom (1997). Promoting positive attitudes of kindergarten-age children toward people with disabilities. Exceptional Children 63: 405-418.

Guralnick, M.J. (1999). The nature and meaning of social integration for young children with mild developmental delays in inclusive settings. Journal of Early Intervention 22: 70-86.

Guralnick. M.J. (2001). An agenda for change in early childhood inclusion. In: M.J. Guralnick (Ed.), Early Childhood Inclusion: Focus on Change (pp. 531-542). Baltimore, Md.: Brookes.

Guralnick. M.J., R.T. Connor, M.A. Hammond, J.M. Gottman and K. Kinnish (1996). The peer relations of preschool children with communication disorders. Child Development 67: 471-489.

Harper, L.V., and K.S. McCluskey (2002). Caregiver and peer responses to children with language and motor disabilities in inclusive preschool programs. Early Childhood Research Quarterly 17: 148-166.

Harter, S., and R. Pike (1984). The Pictorial Scale of Perceived Competence and Social Acceptance for Young Children. Child Development 55: 1,969-1,982.

Kemple, K.M., and M.R. Jalongo (2003). Let's Be Friends: Peer Competence and Social Inclusion in Early Childhood Programs. New York: Teachers College Press.

Killen, M., and C. Stangor (2001). Children's social reasoning about inclusion and exclusion in gender and race peer group contexts. Child Development 72: 174-186.

Killen, M., K. Pisacane, J. Lee-Kim and A. Ardila-Rey (2001). Fairness or stereotypes? Young children's priorities when evaluating group exclusion and inclusion. Developmental Psychology 37: 587-596.

Manetti, M., B.H. Schneider and G. Siperstein (2001). Social acceptance of children with mental retardation: testing the contact hypothesis with an Italian sample. International Journal of Behavioral Development 25: 279-286.

Martin, C.L., D.N. Ruble and J. Szkrybalo (2002). Cognitive theories of early gender development. Psychological Bulletin 128: 903-933.

McDonnell, A.P., K. Brownell and M. Wolery (1997). Teaching experience and specialist support: a survey of preschool teachers employed in programs accredited by NAEYC. Topics in Early Childhood Special Education 17: 263-285.

Nabors, L.A., and L.A. Keyes (1997). Preschoolers' social preferences for interacting with peers with physical differences [brief report]. Journal of Pediatric Psychology 22: 113-122.

Odom, S.L., and K.E. Diamond (1998). Inclusion of young children with special needs in early childhood education: the research base. Early Childhood Research Quarterly 13: 3-26.

Odom, S.L., C. Zercher, S. Li, J.M. Marquart, S. Sandall and W.H. Brown (2006). Social acceptance and rejection of preschool children with disabilities: a mixed-method analysis. Journal of Educational Psychology 98: 807-823.

Okagaki, L., K. Diamond, S. Kontos and L. Hestenes (1998). Correlates of young children's interactions with classmates with disabilities. Early Childhood Research Quarterly 13: 6786.

Ramsey, P.G. (1988). Social skills and peer status: a comparison of two socioeconomic groups. MerrillPalmer Quarterly 34: 185-202.

Ramsey, P.G. (1995). Changing social dynamics in early childhood classrooms. Child Development 66: 764-773. 
Ramsey, P.G., and L.C. Myers (1990). Salience of race in young children's cognitive, affective, and behavioral responses to social environments. Journal of Applied Developmental Psychology 11: 49-67.

Theimer, C., M. Killena and C. Stangor (2001). Young children's evaluations of exclusion in genderstereotypic peer contexts. Developmental Psychology 37: 18-27.

U.S. Department of Education. (2004). Twenty-Sixth Annual Report to Congress on the Implementation of the Individuals with Disabilities Education Act. Washington, D.C. Retrieved January 29, 2007, from http:// www.ed.gov/aboutlreports/annualJosep/2004/index.html

van der Meer, A. (2007). Parent's Guide to Mortifying Moments: Embarrassing Events Every Parent Faces - and How to Get out of Them Gracefully. Retrieved January 29, 2007, from http:/ / www.sesameworkshop.org/ parents/advice/article.php?contentId=912\&

\section{Appendix}

Vignettes in which physical disability interferes substantially:

Some kids are kicking a ball and running in the grass outside. They are having a lot of fun. These kids want to play, too. There's only room for one more kid. Which boy/girl do you think should get to play? This boy/girl (point). S/he uses a walker to help her/him walk. S/he can't run but s/he can kick the ball-or this girl/boy. S/he does not use a walker, so s/he can kick and run. Which would you choose? Why?

Some kids are dancing to $\mathrm{ABC}$ Rock in the classroom with the teacher. These kids both want to dance, too, but the teacher says that there is only room for one more child to join them. Who do you should get to play? This boy - he's in a wheelchair. He can dance by moving his arms-or this boy. He's not in a wheelchair so he can dance with his arms and legs. Both children love to dance and would really like a turn. Which would you choose? Why?

Vignettes in which physical disability interferes moderately:

Some kids are putting a puzzle together on the floor. These two kids want to help them, but the teacher says that only one more child can help. Who do you think should get to help with the puzzles? This boy (in wheelchair). He enjoys putting puzzles together, but he needs help to get out of his wheelchair so that he can sit on the floor to play with the puzzle. Or this boy - he likes putting puzzles together and does not need help to sit on the floor. Why?

These kids are playing with blocks at school. Two boys also want to play with the blocks, but the teacher says that there's only room for one more. Who do you think should get to play? This boy-He's in a wheelchair. He builds really cool buildings, but you will have to move the blocks from the floor to the table so he can play with them. Or this boy - he enjoys playing with the blocks. He can play with the blocks on the floor. Why?

Vignettes in which physical disability interferes minimally:

These kids are playing with the Legos at the table. Two more boys want to play at the Lego table but there is only room for one. Who do you think should get to play? This boy - he sits in a wheelchair when he plays. His wheelchair fits at the Lego table. He may need help picking up Legos if they fall, but he doesn't need help to play. Or this boy - he doesn't need any help to play. Why? 
Some kids are making pictures at the art table. The teacher says that one more child can come to the table to make pictures. Who do you should get to play? This boy - he's in a wheelchair and needs some help picking things up when they fall on the floor, but he doesn't need help making pictures. Or this boy - he wants to make a picture, too. He's not in a wheelchair and won't need any help. Why? 